\title{
Information-Analytical Activity and Its Role in Internal Affairs Bodies
}

\author{
Bakhtiyor Vahobovich Buriev \\ Director of Surkhandarya Academic Lyceum of the Ministry of Internal Affairs of the Republic of Uzbekistan, \\ Uzbekistan
}

http://dx.doi.org/10.18415/ijmmu.v9i2.3537

\begin{abstract}
21 st century is recognized as the age of information. Today, the range of users of information is expanding, and it is becoming the object of interest not only of traditional consumers, i.e. informationanalytical centers, the media and security agencies, but also members of society as a whole. Informationanalytical activity is one of the important directions of practical activity of internal affairs bodies. The success of the task of maintaining public order and combating crime in the service area in many respects depends on the degree to which information and analytical activities are organized. The process of forming the "Information Society" has been going on for several years.
\end{abstract}

Keywords: Information-Analytical Activity; Information-Analytical Work; Information; Criminogenic Situation; Analytical Work; Fight Against Crime; Maintaining Public Order; Organization of Information-Analytical Activity; Operational Situation

\section{Introduction}

It is well known that the 21st century is recognized as the age of information. Today, the range of users of information is expanding, and it is becoming the object of interest not only of traditional consumers, i.e. information-analytical centers, the media and security agencies, but also members of society as a whole. The process of forming the "Information Society" has been going on for several years, and today information has become an integral part of our lives.

Today we live in a time when the ability of every nation to "curb", systematize and analyze information, which is growing every day, determines its place and status in the world community.

From this, it can be said that information has become one of the main tools of power. This has been the case since the discovery of the tendency of the human mind to absorb information. In due time, information is replacing the power and violence that has served as a tool of governance for a long time. As one of the former US Presidents Richard Nixon admitted in the national security Council on the issue of budget expenditures, "a 1 dollar invested in information and propaganda is more valuable than $\$ 10$ invested in the creation of weapons systems, since the latter is unlikely to be ever used in case, while information works hourly and everywhere» [1]. 


\section{Main Body}

Sometimes information is compared to the highest technology product. However, in our view, information has a higher position in the hierarchy of values. We acknowledge that the common phrase "whoever has the information manages the situation" is used in its place.

However, in the implementation of information-analytical activities is a complex process aimed at collecting, summarizing, analyzing important information, rather than raw materials, and timely delivery of the results to the relevant agencies and officials. The facts do not matter much when taken separately. In this case, the importance of competent use of methods and techniques of data collection and analysis is demonstrated.

Information-analytical work is such a creative process that it turns into a finished product for government agencies and officials who make and implement certain decisions related to the planning, control and coordination of specific facts.

The information-analytical activity is carried out to a greater or lesser extent by both the executive and middle management, as well as senior staff. Therefore, at the present time, every employee should know the methods and tools of information-analytical work and be able to use them effectively in the study of emerging situations. Ignoring or not being able to use scientific methods can not only be a waste of time and effort, but can also have a negative impact on making important decisions later on.

Information-analytical work is the process of studying and analyzing problem situations using logical, strategic and mathematical methods and making recommendations for their effective solution.

Analytical work is an activity aimed at assessing all the facts in general and each of them individually by gathering (depending on space and time, cause and effect, etc.) a number of scattered data into one system on a logical basis, which is the main criterion of the daily activities of each leader.

One of the important directions of practical activity of internal affairs bodies is informationanalytical activity. The success of the task of maintaining public order and combating crime in the service area depends in many respects on the level of information and analytical activity.

The content of information-analytical activity consists of studying and analyzing the essence and the causes of events and processes taking place in the administrative territory and their impact on the state and nature of the criminogenic situation, providing internal affairs bodies with information on the operational situation and on this basis to determine the main directions of work on the elimination of negative factors.

Effective work of internal affairs bodies in the fight against and prevention of crime depends on, firstly, the correct organization of information and analytical activities of internal affairs bodies, secondly, the clear definition of tasks related to analytical activities, thirdly, the organization of information and analytical activities of internal affairs bodies and the effective co-operation of other departments and the public in the collection of information [2].

It should be noted that the effective organization and management of information and analytical activities of internal affairs bodies in maintaining public order and ensuring the safety of citizens, combating crime and crime prevention is a complex process.

The complexity of the organization of information and analytical activities of internal affairs bodies:

first, regular review and accurate assessment of the operational situation in the region;

second, timely and effective planning of these activities;

third, regular changes in tactical methods depending on the operational situation in the implementation of activities;

fourth, timely and effective use of scientific and technical innovations; 
fifth, wide introduction of best practices in the organization and implementation of informationanalytical activities;

sixthly, in the organization of information and analytical activities of internal affairs bodies in close cooperation with other departments of internal affairs bodies and the general public.

Effective organization of law enforcement activities includes the collection and analysis of information, decision-making based on them, crime prevention and planning, as well as the correct assessment of the results achieved, the organization and control of the implementation of decisions. The effective organization of information and analytical activities of internal affairs bodies depends, first of all, on the completeness, reliability and quality of the information received. Therefore, they are required to identify, collect and thoroughly analyze all the information about the objects to which preventive measures should be directed in the first place.

The specific features of the information-analytical activity of internal affairs bodies are: first, in adapting to the operational situation in the prevention of crime and familiarization with the main tasks and methods; second, in eliminating the impact of false information that prevents crime; thirdly, it is reflected in the management of the activities of various agencies, institutions, public organizations, citizens' selfregulatory bodies for crime prevention [3].

It should be noted that the role of information and information technology plays an important role in the effective organization of information and analytical activities of internal affairs bodies. In particular, complete and accurate information on possible offenses, including crimes, is a guarantee of the success of crime prevention measures [4].

They analyze the information received on the tasks of internal affairs bodies and use them effectively in their work. However, analytical activity is a research and cognitive activity that is necessary to justify decisions and evaluate the effectiveness of the system, as well as to identify causal relationships, principles and laws.

The purpose of the analytical activity is to develop and justify various management decisions, as well as to understand the general principles and phenomena of practice. Also, it is important in the development of measures to prevent from crimes and predictions of future crime based on analytical activity. After all, criminological forecasting is a creative process in which, on certain grounds, new directions for the prevention of currently committed crimes and conclusions about the prevention of future crimes are formed. The internal affairs bodies make decisions on the analysis of information obtained in the information-analytical activity and the implementation of crime prevention measures on the basis of the criminological forecast developed on its basis. These decisions have the operational nature of making changes and additions to general and individual crime prevention measures, the tactical nature of changing and using new methods of priority prevention tasks, considering the specific criminogenic situation, and are intended for long term on the development of comprehensive crime prevention measures [5].

Almost all services included in the system of internal affairs agencies are engaged in information and analytical work. In addition, some services (criminal investigation and counter-terrorism, investigation, crime prevention and other services) have separate departments (divisions) for this purpose.

The effectiveness of the structures that provide this information-analytical work depends on the degree to which the process of studying the current operational situation and the current problems in the fight against crime arising from its analysis is well organized.

In the legal literature, the content of analytical work in internal affairs bodies is defined as research and cognitive activity, which includes the study and evaluation of information on the state of law and order and the results of practical activities of internal affairs bodies, the external environment in which this activity takes place [6]. 
Information-analytical work, on the one hand, allows to identify the negative social phenomena (crime, public disorder, etc.) occurring and study their laws, and on the other hand, reflects the results of the daily activities of services and structures to combat these phenomena.

In other words, it consists of, first, an analysis of the state of crime and public order over a period of time, second, to study the effectiveness of each particular form used in the fight against crime and the practical feasibility, the areas of activity for the implementation of the tasks facing internal affairs bodies.

Analyzing and evaluating the results of the activities of a particular police department is one of the most complex and responsible stages of the analysis process. Because it is the answer to the question of how the organ and its specific links perform their main function, how effectively they function. The analysis of performance (both qualitatively and quantitatively) is based on the existing criteria and indicators in the system of internal affairs, defined by departmental regulations.

Assessment of activity on the basis of one or another criterion can be expressed in terms of quantitative indicators (criteria for assessing the quality of the preliminary investigation, in particular, the return of criminal cases for additional investigation, unfounded accusations, the amount of illegal precautionary measures).

In analytical work, two territorial bodies or two departments (division) with similar characteristics of the work performed by one body have the same human and material resources and operate under the same conditions, but, according to the results of their work, the method of comparative study of the activities of two or more preventive inspectors, duty units, investigative and operational teams, which are quite different from each other, give high efficiency.

The general goal for such research is to compare the forms and tactical methods of organizing specific work, the most important questions - why the results are radically different when conditions, forces and means are the same, what hinders those left behind to work well, to find answers to questions such as what is the reason for getting stuck in one place, what should be done to make the work work well; identification and dissemination of positive experiences, the development of a clear management decision of the head of the body based on the results of the study. The subject of comparative research can be various areas (crime prevention, detection and investigation, search for criminals and missing persons, results of the fight against crime, etc.) of operational activities (methods and techniques of work, efficiency of power and tool management, etc.), as well as organizational work of heads of services, structures [7].

The problems that require comparative research are often encountered when studying statistics on the crime situation and the results of the fight against it. At the same time, a crisis situation arises when some structures, their managers or employees have high performance, while others have the opposite. An analyst who notes this situation will study the conditions under which they perform their service duties, and if they are similar to each other, there will be grounds for conducting a comparative study. In studying the problem, the causes of the phenomenon under investigation should be clear, the existing interrelationships and interdependencies should be disclosed. In other words, there should be no "white spots" left in the problem under study.

Comparing the crime scene and the situation with the activities of the services and structures of the Ministry of Internal Affairs, for example, it is advisable to conduct another type of comparative analysis by comparing street crimes, traffic accidents patrol-post patrols, the direction of movement of traffic patrols of the State Traffic Safety Service.

The following indicators play an important role in assessing the performance of operational services:

- information on the amount of operational activities, activities, etc. (they describe the scope of operational activities); 
- indicators reflecting the results of the use of force and means in the implementation of operational activities (they include the use of technical means, personnel and auxiliary forces, money and material resources, various loads and time spent, etc.);

- an indicator of the amount of different requirements for the conduct of procedural actions in the course of service (for example, the duration of the inquiry, the loading of personnel, etc.).

The information-analytical work carried out in the internal affairs bodies should not be limited to the recording of completed events and, above all, it should serve to identify unavoidable negative developments in the field of law enforcement in a timely manner and thereby reconsider the operational and preventive measures previously developed to redistribute existing forces and means and to prevent such incidents in the future.

It should be noted that when talking about the current state of information and analytical work of internal affairs bodies, it can be observed that the work in the field of information collection, processing, storage and protection in the system does not fully meet the requirements as well as the activity is linked to reports. Despite repeated criticism of the Ministry of Internal Affairs of the Republic of Uzbekistan by the leadership of the Ministry, in practice, some police chiefs try to present their report as well as possible, to hide negative aspects of the work process, and some managers try to falsify reporting figures. This, of course, has a negative impact on the quality of the analysis, as a result, timely identification of existing shortcomings and problems prevents them from taking measures to eliminate them, leads to misguided management decisions [8].

In this regard, in order to improve the information-analytical work, it is possible to suggest the following measures:

First, it is necessary to expand the content and ideological scope of information-analytical work in the practice of internal affairs bodies. Because information-analytical work regularly studies the operational situation in the region, it includes not only writing an analytical report and assessing the situation, but also conducting scientific research, especially research on new issues that internal affairs bodies have not encountered before.

Second, to identify promising forms and methods of information-analytical work of internal affairs bodies and to disseminate it throughout the system. To this end, it is appropriate to establish an independent departmental scientific-practical publication on information-analytical issues or to open and use it in existing departmental publications, on the other hand, to hold regular scientific-practical seminars on information-analytical support of internal affairs bodies and set out to publish their results.

Third, the efforts of the scientific community and mature professionals and scientists in the field should focus on the problems of analyzing and forecasting the crime situation. In this regard, it is expedient to develop a network program of research on information and analytical support of internal affairs bodies, using a systematic method that allows to study the impact of socio-economic situation on the criminogenic situation in the form and confirmation of interaction of structural units.

\section{Conclusion}

In conclusion, it should be noted that the proper organization of information and analytical work, which is one of the important areas of practical work of internal affairs bodies, based on research methods, will further improve the multifaceted activities of law enforcement officers in the fight against crime. This, in turn, paves the way for the creation of an image of a law enforcement agency that "literally serves the interests of the people" on the basis of large-scale reforms carried out under the slogan "New Uzbekistan - a new law enforcement agency." 


\section{References}

1. Paramonov V.V. Fundamentals of information and analytical work. Tashkent, Higher School of Strategic Analysis and Forecasting, 2002.

2. Ismailov I., Zièdullaev M.Z. et al. Fundamentals of information-analytical activity: Textbook. Tashkent, 2015

3. Ziyodullaev M., Mukhtorov J., Yuldashev J. and others. Activities of law enforcement agencies: Textbook. - Tashkent, 2021.

4. Kadirov F. The importance of the use of information technology in crime prevention // Current issues in crime prevention. Materials of the Republican scientific-practical conference. November 28, 2003. Tashkent.: Academy of the Ministry of Internal Affairs of the Republic of Uzbekistan, 2003.

5. Zaripov Z.S., Ismailov I. Criminology. Tashkent., 1996

6. Pulatov Yu. S., Ismailov I. U., Qurbonov A. Fundamentals of Management in Internal Affairs: Textbook. Tashkent., 2005.

7. Talkhigova L. Improvement of information and analytical work in the Department of Internal Affairs. Grozny., 2011.

8. Shoyjigitov A., The essence of information-analytical work of law enforcement agencies and some comments on its improvement: Bulletin of the Academy of the Ministry of Internal Affairs of the Republic of Uzbekistan. 2013. №2.

\section{Copyrights}

Copyright for this article is retained by the author(s), with first publication rights granted to the journal.

This is an open-access article distributed under the terms and conditions of the Creative Commons Attribution license (http://creativecommons.org/licenses/by/4.0/). 